\title{
The Prevalence of Pseudomonas Aeruginosa Strains in Infants With Cystic Fibrosis in a Hospital from North Easter Romania
}

\author{
Oana - Alexandra CIOCAN (MOŢCO) ${ }^{1 *}$, Alper ÇIFTÇI ${ }^{4}$, Mihai CARP - CĂRARE ${ }^{1}$, Mihai MAREŞ ${ }^{1}$, Eleonora \\ GUGUIANU $^{1}$, Ioana CRIVEI ${ }^{1}$, Carmen - Valentina PANZARU ${ }^{3}$, Cătălin CARP - CĂRARE ${ }^{1}$ \\ ${ }^{1}$ Faculty of Veterinary Medicine, Iasi \\ 2"Grigore T. Popa" University of Medicine and Pharmacy Iasi \\ ${ }^{3}$ University of Ondokuz May's, Faculty of Veterinary Medicine, Department of Microbiology, Turkey \\ *corresponding author: veterinarians_phd@yahoo.com
}

\begin{abstract}
Cystic fibrosis (CF) is the most common autosomal recessive genetic disease caused by mutation of the CFTR gene. In Romania, CF disease has an estimated a prevalence of 1 case per 2500 live births. Approximately $50 \%$ of children die in early life, so the exact number of CF patients in our country remains unknown as no national patient registry exists. This situation has limited our knowledge about the disease progression. Complicated with $P$. aeruginosa leads to long progressive diseases and often aggravates morbidity and mortality.

The aim of the study was to phenotypically identify the P. aeruginosa strains, according to their antibiotic susceptibility profile in order to administer more precisely the antibiotics and to avoid development of multidrugresistant strains.

After the diagnosis of CF, the patients return to a medical control at every 3 months. The sputum samples are collected from these patients, in order to perform the bacteriological examination and the DST test. This study was performed during 1 year (01.01-31.12.2015), and all the sputum samples were cultivated on usual and on special culture media to establish more precisely the type of isolated bacteria. The confirmation was performed using the API 20 NE biochemical test and classified in resistance phenotypes according to CLSI 2015 standards.

The study population was represented by 85 infants with CF, from which we isolated 364 bacterial strains. $10.16 \%$ of the total bacterial strains were represented by P. aeruginosa.

A major problem represents the repeated antibiotic treatments, this being favourable for the emergence of resistant strains. Antibiotic resistance is currently one of the most important problems faced by clinicians (Moskowitz et al., 2004). Multidrug-resistant (MDR) strains of $P$. aeruginosa were identified in this study and we highlighted that this strains limits the antimicrobial treatment and is shortening the patient's life (9).
\end{abstract}

Keywords: cystic fibrosis, prevalence, Pseudomonas aeruginosa

\section{INTRODUCTION}

Cystic fibrosis (CF) - the most frequent autosomal recessive disorder of the Caucasian population, is a complex disease, Often, the respiratory tract is the most affected and the lung disease is characterized by chronic infections (positive cultures after 6 months of germ isolation) or recurrent infections, inflammation and development of bronchiectasis (Kirkby et al., 2009)

The lungs of the patients with CF are the home of numerous bacterial infections, Pseudomonas aeruginosa being dangerous bacteria detected in 
the respiratory tract of these children (Paduraru et al., 2014).

The objective of this study was to identify children with $\mathrm{CF}$ and P. aeruginosa infection and to quantify the impact of this infection on their clinical status, the MDR prevalence in these children, as well as the chronic $P$. aeruginosa MDR infection impact on the lung.

\section{MATERIAL AND METHODS}

The prospective study between 1 January 2015 and 31 December 2015 was carried out on a group of 85 children suffering from $\mathrm{CF}$, registered in the records of the hospital. All patients with $\mathrm{CF}$ were submitted to the micro-bacteriological test of the aspirate or the sputum for P. aeruginosa. All the sputum samples were cultivated on usual culture media (blood agar, chocolate agar, MacConkey) and on special culture media (selective Pseudomonas Agar CN-Oxoid), PAID media, for establish more precisely the Pseudomonas aeruginosa.(Fig. 1.) (Ciocan et al., 2014)

The confirmation was performed using the API $20 \mathrm{NE}$ biochemical test and finally classified in resistance phenotypes according to CLSI 2015 standards.(Fig. 2.)

The resistance of strains was determined by testing sensitiveness to major classes of antibiotics with micro-caplets on the Mueller-Hinton medium at $37^{\circ} \mathrm{C}$ for 24 hours. (Fig. 3.) (Ciocan et al., 2015)

Criteria for defining MDR, XDR and PDR in Pseudomonas aeruginosa MDR: non-susceptible to 1 agent in 3 antimicrobial categories, XDR: nonsusceptible to 1 agent in all but less 2 categories, PDR: non-susceptible to all antimicrobial agents listed (Magiorakos et al., 2011).

\section{RESULTS AND DISCUSSIONS}

The study population was represented by 85 infants with CF, from which we isolated 364

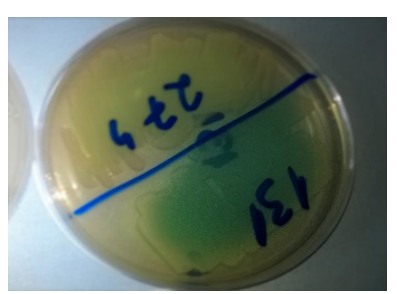

Usual agar

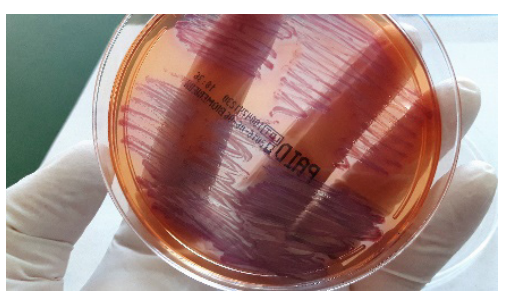

PAID

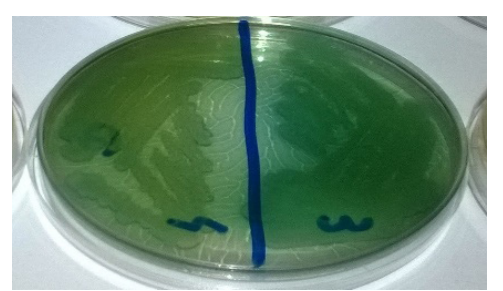

P.a. Agar CN-Oxoid

Fig.1. Strains of Pseudomonas aeruginosa on diverse cultural media
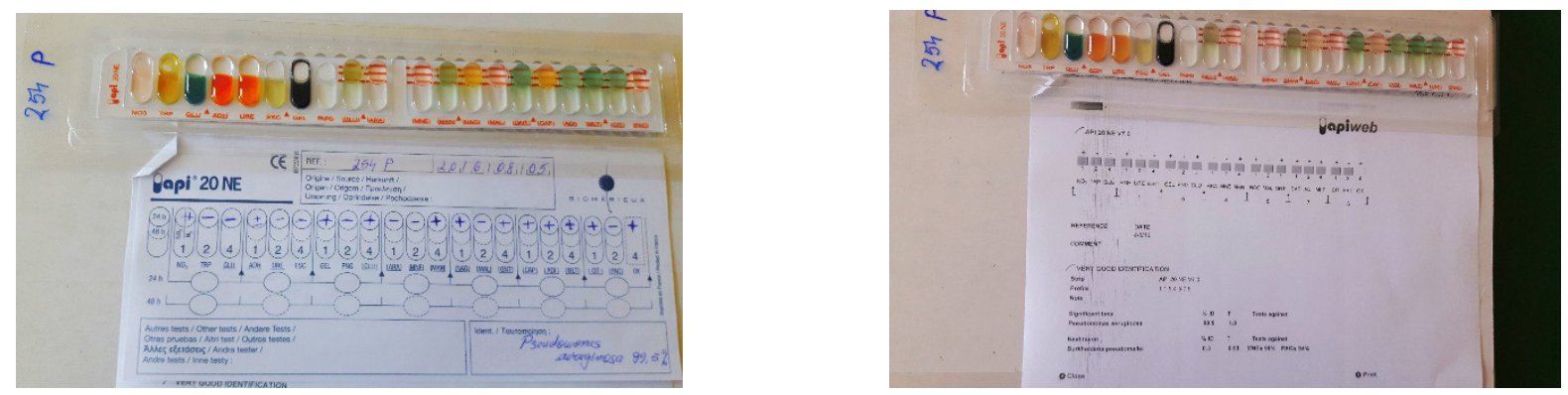

Fig. 2. Biochemical confirmation of Pseudomonas aeruginosa strains
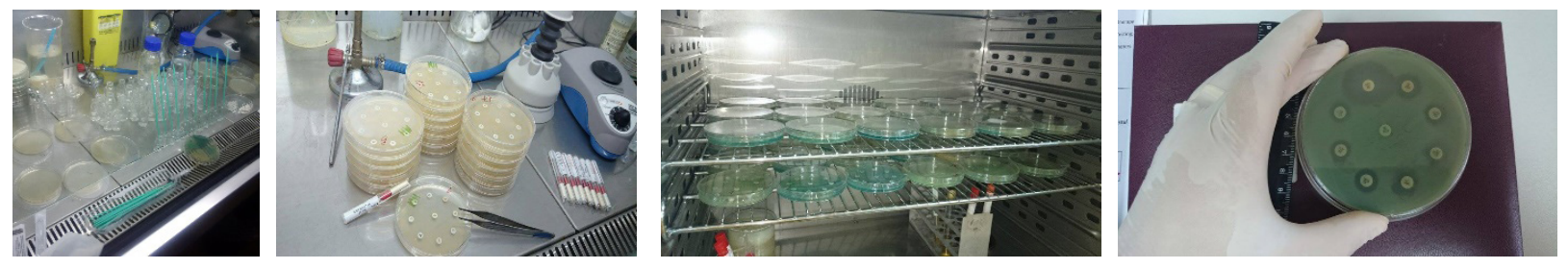

Fig. 3. Disc diffusion method for testing antimicrobial activity 
Tab.1. Antimicrobial categories and agents used to define MDR, XDR and PDR (Magiorakos et al., 2011)

\begin{tabular}{|c|c|}
\hline $\begin{array}{c}\text { Antimicrobial category } \\
\text { Aminoglycosides }\end{array}$ & $\begin{array}{c}\text { Antimicrobial agent } \\
\text { Gentamicin }\end{array}$ \\
\hline $\begin{array}{c}\text { Tobramycin } \\
\text { Amikacin }\end{array}$ & \\
\hline Netilmicin & \\
\hline Antipseudomonal carbapenems & $\begin{array}{l}\text { Imipenem } \\
\text { Meropenem }\end{array}$ \\
\hline Antipseudomonal cephalosporins & $\begin{array}{l}\text { Ceftazidime } \\
\text { Cefepime }\end{array}$ \\
\hline Antipseudomonal fluoroquinolones & $\begin{array}{l}\text { Ciprofloxacin } \\
\text { Levofloxacin }\end{array}$ \\
\hline Antipseudomonal penicillins $+b$ & lactamase inhibitors \\
\hline & $\begin{array}{l}\text { Ticarcillin-clavulanic acid } \\
\text { Piperacillin-tazobactam }\end{array}$ \\
\hline Monobactams & Aztreonam \\
\hline Phosphonic acids & Fosfomycin \\
\hline Polymyxins & Colistin \\
\hline & Polymyxin B \\
\hline
\end{tabular}

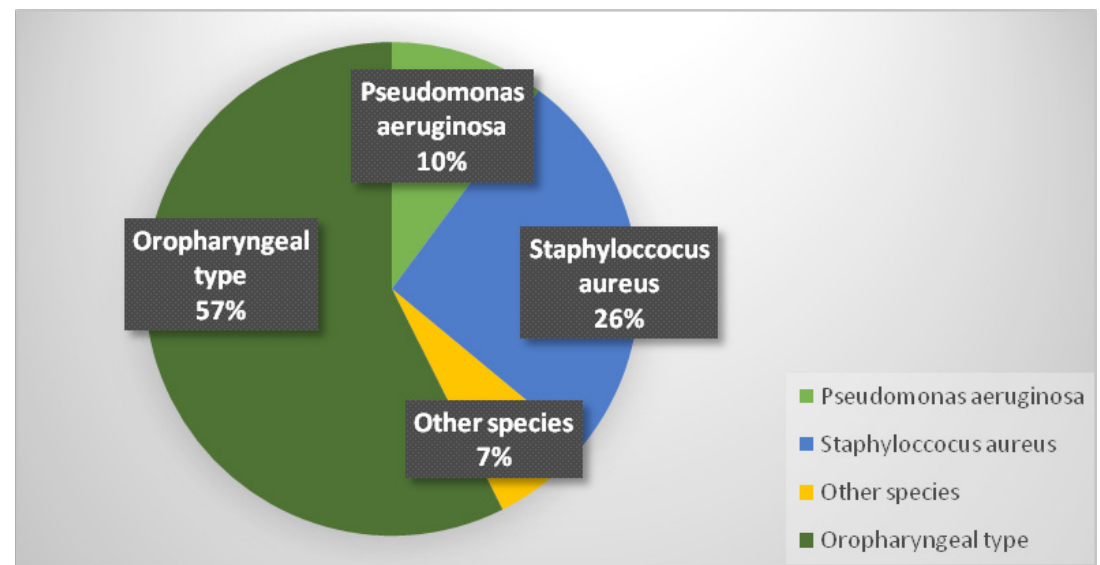

Fig. 4. Total of bacterial strains isolated from infants with CF

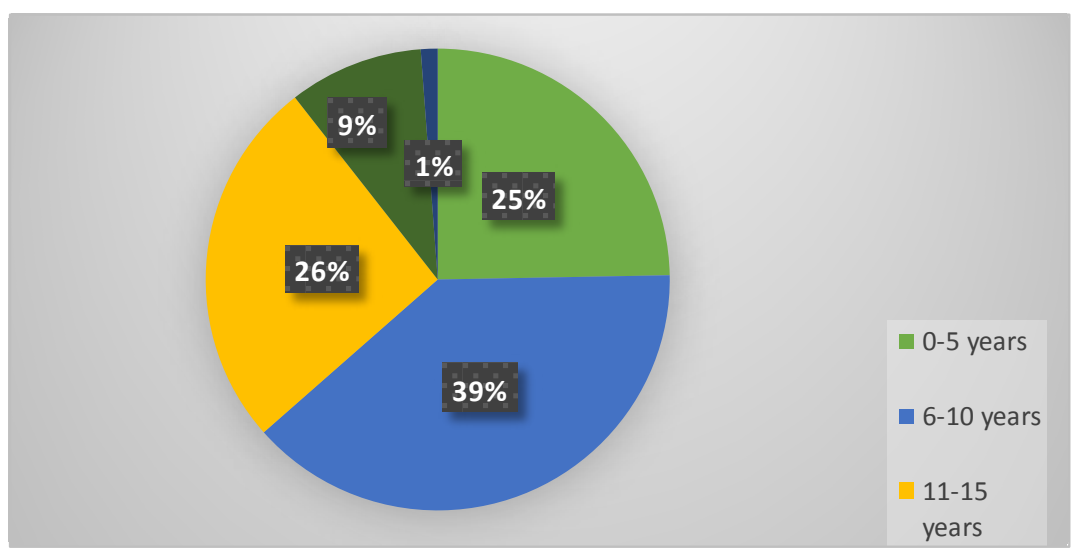

Fig. 5. Graphical representation of age groups 
bacterial strains. $10 \%$ of the total of bacterial strains were represented by P. aeruginosa. (Fig. 4)

Colonization of lung with Pseudomonas aeruginosa strains depends on dissimilar number of factors, children from group with 6 years to 10 years are the most likely infected with Pseudomonas aeruginosa in this study. (Fig. 5)

MDR microorganisms are an important issue in the care of patients with CF. Each patient infected with such strains should be assessed individually

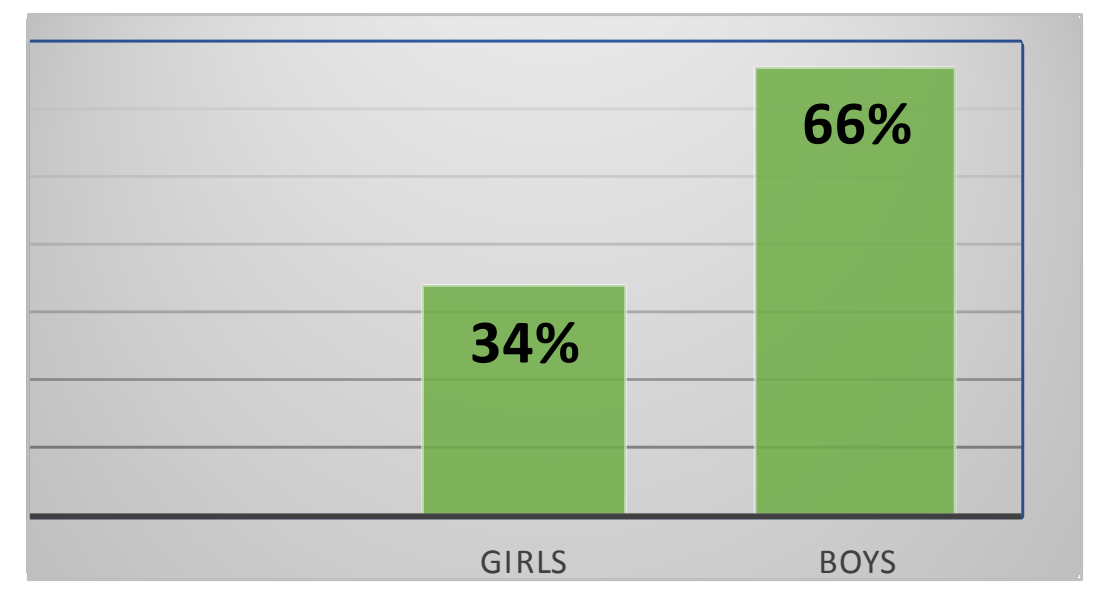

Fig. 6. Graphical representation depending on the sex of the child with CF

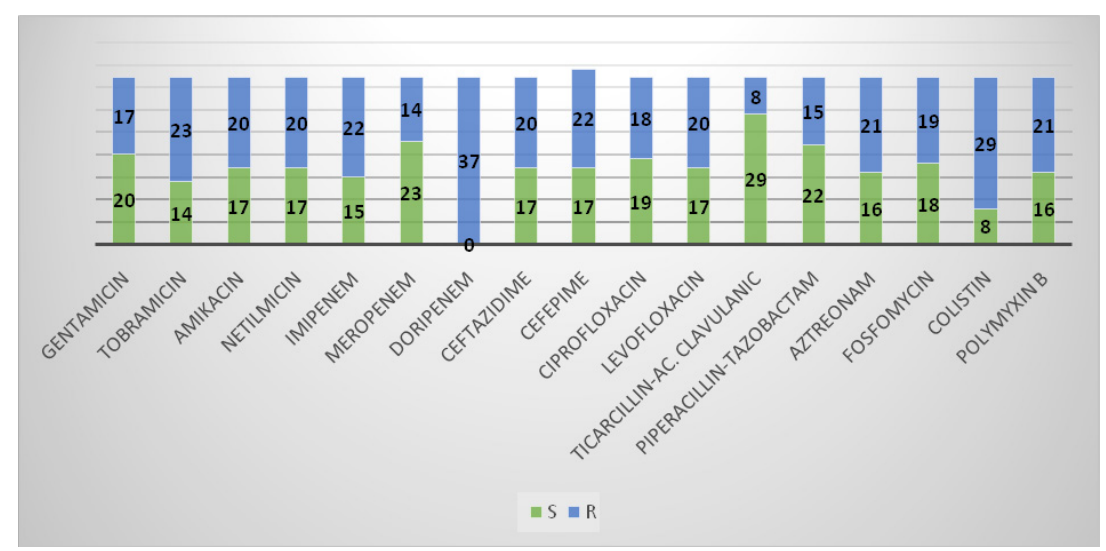

Fig. 7. Results of antibiotic susceptibility of Pseudomonas aeruginosa strains

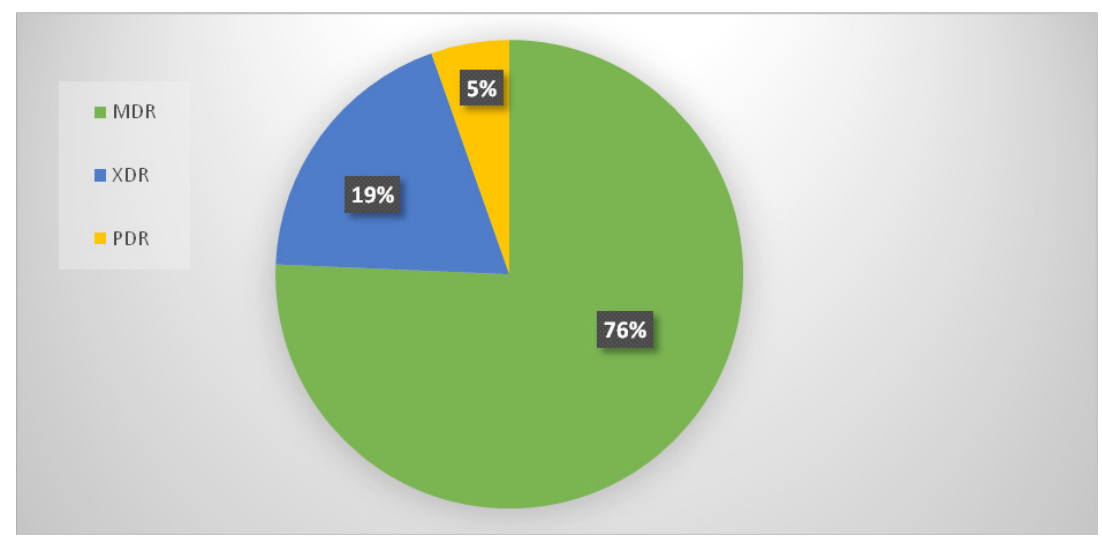

Fig. 8. Phenotypic identification of Pseudomonas aeruginosa strains 
and antibiotic treatment administrated according to the results of antibiotic susceptibility. (Fig. 7)

\section{CONCLUSIONS}

For a more accurate and rapid isolation we recommend using Pseudomonas culture medium $\mathrm{CN}$ Oxoid and for sputum PAID chromogen medium, even if it is more expensive;

In our study, $10 \%$ of the total bacterial strains were represented by $P$. aeruginosa;

Following the results of antibiotic susceptibility in the current study prevailed MDR strains;

Resistance to colistin is low and this antibiotic should be considered as a valuable secondline drug to be used for multidrug-resistant $P$. aeruginosa;

Treatment of MDR strains is difficult and sometimes without therapeutic success. MDR strains become PDR if antibiotics are not used according to the antimicrobial test. Combined antibiotic therapy is recommended, but the choice of treatment regimen should always be guided by the clinical response of patient's.

According to the schedule in which age groups are represented, group 6-10 years is the most affected, and boys are more infected than girls;

To check if these parameters are relevant must be checked a much larger number of children and over a longer time interval.

\section{REFERENCES}

1. Magiorakos AP, Srinivasan A, Carey RB, Carmeli Y, Falagas ME, Giske GC, Harbarth S, Hindler JF, Kahlmeter G, OlssonLiljequist B, Paterson DL, Rice LB, Stelling J, Struelens MJ, Vatopoulos A, Monnet DL (2012). Multidrug-resistant, extensively drug-resistant and pandrug-resistant bacteria: an international expert proposal for interim standard definitions for acquired resistance, Clin Microbiol Infect 18(3):268-81

2. Ciocan (Moțco) OA, Carp Cărare M, Panzaru CV, Petraru E (2014). Classifying Pseudomonas aeruginosa strains of animal origin in MDR, XDR and PDR by determining the resistance to antibiotics, Lucrări Stiinţifice USAMV Iaşi Seria Medicină Veterinară, 57 (nr.1-2) 200-204.

3. Ciocan (Moțco) OA, Carp Cărare M, Cozma AP, Carp Cărare C, Rîmbu C, Coman G, Petraru E, Panzaru CV (2015). Isolation and identification of Pseudomonas aeruginosa strains producing $\beta$-lactamases (ESBL) and carbapenemases (MBL) of human origin, Bucharest, Scientific Works. Series C. Veterinary Medicine. Vol. LXI (2) DOI: 10.13140/RG.2.1.4894.1605

4. Ciocan OA, Cozma AP, Lipovan (Abalasei) I, Guguianu E, Panzaru CV, Mareș M, Carp Cărare M, Carp Cărare C (2015). Antibiotics resistance dynamics of isolated Pseudomonas aeruginosa strains in a hospital from north eastern Romania in the period 2012 - 2014, Lucrări Stiințifice vol. 58 Medicină Veterinară partea 3 / 469-473

5. Conway SP, Brownlee KG, Denton M, Peckham DG (2003). Antibiotic treatment of multidrug-resistant organisms in cystic fibrosis, Am J Respir Med 2(4):321-32.

6. Kirkby S, Novak K, Mc Coy K (2009). Update on antibiotics for infection control in cystic fibrosis. Expert Rev Anti Infect Ther 7(8):967-80.

7. Moskowitz SM, Foster JM, Emmerson J, Burns JL (2004). Clinically feasible biofilmsusceptibility assay for isolates of Pseudomonas aeruginosa from patients with cystic fibrosis.J Clin Microbiol 42, 1915-1922

8. Paduraru D T, Moscalu M, Coman G, Coman,Florescu L, Tradafir L (2014). The Impact of the Staphylococcus Aureus Infection on the evolution of children with Cystic Fibrosis from a Regional Centre in North-Eastern Romania, Revista Românå De Pediatrie Volumul LXIII, Nr.

9. Antimicrobial Resistance and Healthcare-associated Infections Programme - See more at: http://ecdc.europa. eu/en/activities/diseaseprogrammes/ARHAI/Pages/ index.aspx\#sthash.1E9JZPvW.dpuf 